\title{
Novas Perspectivas da Docência no Ensino Superior: a importância da Tutoria Presencial em curso de Licenciatura em Educação a Distância
}

\author{
Leonardo Rocha de Almeida - UNILASALLE/RS - E-mail: \\ leonard.rocha@hotmail.com \\ Rafael Schilling Fuck - UNISINOS/RS - E-mail: rafaelschillingf@gmail.com
}

Resumo. Este artigo visa apresentar uma análise sobre um novo sujeito no Ensino Superior, o Tutor Presencial, profissional que atua muitas vezes como "professor" na modalidade de Educação a Distância, no que se refere às atividades nos polos de apoio presencial. Tendo em vista o crescimento da oferta de cursos dessa modalidade, considera-se fundamental problematizar as atribuições deste profissional. São realizados uma retomada de conceitos sobre a tutoria e, posteriormente, o levantamento de opiniões de alunos, que realizam ou realizaram cursos de licenciatura a distância, sobre a atuação do Tutor Presencial. Foi possível perceber que a atuação do Tutor Presencial é relevante para os alunos e, em alguns momentos, fazem referência a ele nas funções de professor, o que gera um espaço de problematização, ainda, necessário sobre sua caracterização.

Palavras-chave: Tutoria, Ensino Superior, Educação a Distância.

\section{New Perspectives of Teaching in Higher Education: the importance of Presencial Tutoring in Teacher Degree in Distance Education}

Abstract: This article presents an analysis of a new professional into Higher Education, the Presencial Tutor, professional acting often as a "teacher" in the modality of the Distance Education, as it relates the activities at the Polos Presential Support. In view of the growing supply of courses in this modality, it is considered essential problematise about the duties of this professional. Are carried out a resumption of concepts of tutoring and afterwards, the survey of opinions of students who perform or graduated honors degree of distance learning courses on the performance of Presencial Tutor. It was possible to note that the work of the Presencial Tutor is relevant to the students and, at times, make reference to it in teacher functions which generates a problematic space also needed on its characterization.

Keywords: Tutoring, Higher Education, Distance Education.

\section{Introdução}

Este artigo tem por finalidade apresentar uma discussão sobre um novo profissional que surge nas relações da docência no Ensino Superior: o Tutor Presencial. $\mathrm{O}$ interesse de aprofundamento sobre o tema surgiu a partir de um trabalho anterior (ALMEIDA, 2015), no qual se realizou um relato sobre a importância do tutor no bom desenvolvimento de cursos de modalidade $\mathrm{EaD}$ para a permanência e finalização do curso pelo aluno. No referido trabalho, o Tutor Presencial foi definido como:

Restringia-se, inicialmente, à organização administrativa, no polo de apoio presencial, das frequências de entrega de atividades no ambiente virtual em que era realizado o curso, Moodle institucional, elaboração das listas de chamada e arquivamento dos documentos dos cursistas. Além disso, 
adiciona-se o contato constante com os alunos para saber sobre as dificuldades e o que os levava a não entrar no ambiente virtual e participar dos fóruns promovidos pelo professor do módulo (ALMEIDA, 2015, p.1)

Essas atividades foram, gradativamente, criando uma aproximação com os alunos para que eles pudessem perceber a relevância do curso, o qual se caracterizava por uma formação continuada para professores da rede pública. A partir disso, observou-se a função de Tutor Presencial para fomentar as relações dos cursistas e, questionou-se se esse profissional não seria um professor, ao invés de um "tutor", pois o contato com os alunos no polo de apoio presencial estabelecia, de certa forma, uma relação de professor-aluno.

Atualmente, os cursos de Ensino Superior a Distância, em sua maioria, contam com um profissional para realizar a função de tutoria nos polos de apoio presencial, local no qual o aluno tem contato presencial com os demais colegas e com o tutor que vai auxiliar em suas dúvidas durante o curso, além de auxiliá-lo na realização de atividades disponibilizadas online.

Para Emerenciano, Sousa e Freitas (2001, p. 7):

A tutoria caracteriza-se por seu caráter solidário e interativo, possibilitando o relacionamento da pessoa como um ser existente e vivenciado como eu, tu, nós e outros, do que decorre em conjunto de dificuldades, inclusive para colocar-se "entre" outros, como uma presença que se põe intencionalmente.

Assim, a prática da tutoria busca mediar as relações entre o sujeito que procura o curso e a instituição que desenvolve os conteúdos, as aulas e os materiais para que, assim, o aluno possa aprender e alcançar os objetivos que são esperados pelo curso escolhido. Nesse sentido, pode-se perceber que o tutor, como relatado anteriormente, é concebido pelos autores como "alguém que possui duas características essenciais: domínio do conteúdo técnico-científico e, ao mesmo tempo, habilidade para estimular a busca de resposta pelo participante" (ibidem, p.7). Desse modo, tem-se os sujeitos que iniciam sua trajetória profissional no Ensino Superior à Distância na função de tutores, tendo como responsabilidades acompanhar e orientar os alunos, mas não recebendo, institucionalmente, a outorga de professor, junto de seus benefícios.

Para dar seguimento a pesquisa, foi realizado um levantamento junto a grupos de alunos, em fluxo contínuo, para averiguar suas perspectivas da tutoria presencial.

\section{Método e procedimentos}

Empreendeu-se uma investigação de cunho qualitativo (BOGDAN; BIKLEN, 1994; LUDKE; ANDRÉ, 2013), na qual a coleta de dados foi obtida por meio de questionário online ${ }^{1}$ contendo questões abertas e fechadas, divulgado em fluxo contínuo para os sujeitos participantes que contemplassem o perfil de estudante ou formado em licenciatura realizada na modalidade de Educação a Distância. Esses sujeitos foram contatados por e-mails enviados para polos vinculados a programas de formação por Educação a Distância, da região metropolitana de Porto Alegre, solicitando a divulgação aos acadêmicos dos cursos de licenciaturas matriculados e egressos.

A pesquisa de natureza qualitativa se caracteriza pela riqueza de dados descritivos, possui um "plano aberto e flexível e focaliza a realidade de forma complexa e contextualizada" (LUDKE; ANDRÉ, 2013, p. 20). Assim sendo, serão empregadas as

\footnotetext{
${ }^{1}$ Questionário confeccionado em Formulário Google.
}

V. $14 \mathrm{~N}^{\circ}$ 2, dezembro, 2016 
questões fechadas para contextualizar o grupo e as abertas para conhecer as expressões dos sujeitos que constituem o foco da investigação.

Entende-se as questões fechadas como aquelas que são constituídas de "um conjunto de alternativas de respostas para que seja escolhida a que melhor representar a sua situação ou ponto de vista" (SILVA; URBANESKI, 2009, p. 57), enquanto que as abertas são aquelas que "se deixa um espaço em branco para que a pessoa escreva sua resposta sem qualquer restrição" (ibidem, p. 58).

Ao acessar o questionário, o respondente era direcionado à primeira tela, na qual continha um texto introdutório sobre o estudo para que o interessado pudesse realizar a escolha de participar da pesquisa, primando para que compreende as implicações da pesquisa apresentadas no termo de consentimento livre e esclarecido.

As questões posteriores foram divididas em dois blocos. $\mathrm{O}$ primeiro para que o participante identificasse idade, curso e instituição, sendo estes dados utilizados apenas para fins de agrupamento dos respondentes e que não seriam utilizados os nomes destas instituições neste ou em trabalhos posteriores. O segundo bloco consistia de um conjunto de questões para conhecer a concepção dos alunos sobre a função do Tutor Presencial para lhes orientar e auxiliar no desenvolvimento das atividades. Ainda, pretendeu-se, a partir dessas questões, identificar se os alunos conheciam a formação do tutor e quais as expectativas que faziam em relação a este profissional.

\section{Descrição e análise dos resultados}

Conforme mencionado anteriormente, o questionário foi elaborado e estruturado por meio de um aplicativo online para ser enviado aos sujeitos participantes por $e$-mail. $\mathrm{O}$ instrumento apresentava, inicialmente, o Termo de Consentimento Livre e Esclarecido e, logo em seguida, a questão "Você cursa ou cursou um curso de licenciatura na modalidade de educação a distância (EAD)?". Procedeu-se desse modo com o intuito de realizar o primeiro recorte do grupo de participantes e para, posteriormente, apresentar os blocos de perguntas que serão minuciosamente apresentados.

De acordo com a análise dos questionários, foram obtidas 23 respostas válidas das 24 enviadas, pois não contemplava os critérios de inclusão: "Ser aluno/egresso de curso de licenciatura a distância". O grupo de respondentes é composto por pessoas com idade entre 25 e 49 anos. A grande parcela dos respondentes, 17 pessoas, tem mais de 30 anos, o que influenciou a forma de expressão nas questões abertas posteriores (Figura 1).

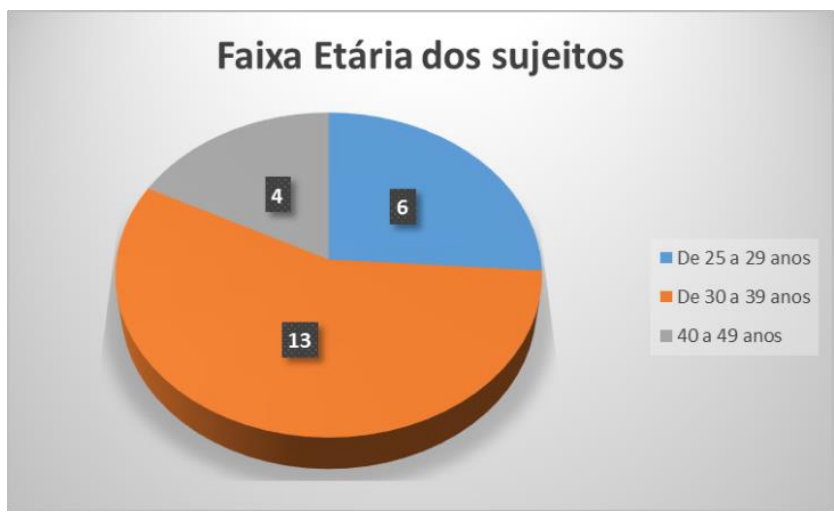


Figura 1 - Faixa etária dos respondentes ${ }^{2}$

Fonte: o pesquisador

Sobre a origem desses respondentes, tem-se a divisão entre instituições públicas e privadas (Figura 2).



Figura 2 - Tipo de Instituição dos respondentes

Fonte: o pesquisador

Esse contexto institucional em que se inserem os respondentes aponta aspectos importantes para conhecer, pois há diferenças nas configurações entre os cursos ofertados em instituições públicas e privadas. As públicas, em geral, selecionam profissionais para atuarem como tutores presenciais por meio de editais. Essa oportunidade pode ser vista por muitos como a forma de ingressar na carreira de magistério superior.

Todos os respondentes assinalaram ter um Tutor Presencial. Entretanto, nem todos possuíam conhecimento sobre a formação de seu tutor. Desse modo, percebe-se que o Tutor Presencial poderia não ter formação adequada para atuação como tutor, embora existam especificidades para diferentes cursos. Por exemplo, uma respondente apontou que sua tutora era formada em Educação Física e realizava tutoria para curso de História. Assim, acredita-se que pela formação em licenciatura, pudesse ocorrer essa transição entre a formação e a atuação, buscando garantir um mínimo de aderência do profissional ao curso.

A periodicidade do atendimento e disponibilidade do Tutor Presencial no polo de apoio presencial, também, foi questionada aos participantes do estudo (Figura 3). De acordo com os respondentes, respondentes a maioria dos tutores atendiam até 3 dias na semana, pensando na forma como a docência se dá na contemporaneidade o tempo curto de atendimento para um curso de graduação a distância é algo que pode prejudicar pelo pouco tempo, porém, como se trata dos alunos apresentando suas perspectivas sobre o trabalho do tutor, eles não tiveram acesso ao contrato do profissional para saber se os mesmos teriam período de planejamento para suas atividades junto aos alunos.

\footnotetext{
${ }^{2}$ Foi realizada a partir de questão de múltipla escolha para a faixa de idade em que se encontrava o respondente.
} 


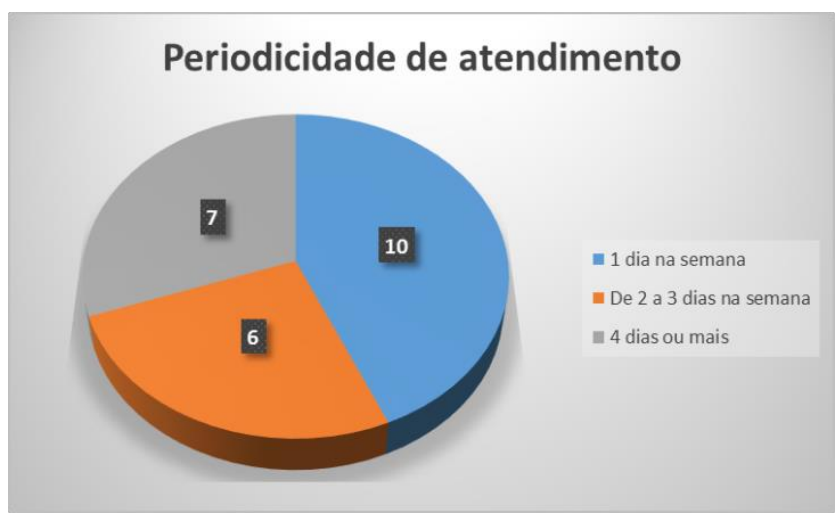

Figura 3 - Periodicidade de atendimento dos tutores

Fonte: o pesquisador

O período de planejamento, de acordo com a Lei de Diretrizes e Base da Educação (BRASIL, 1996), em seu Art. 65, define: "V - período reservado a estudos, planejamento e avaliação, incluído na carga de trabalho". Todavia, como mencionado anteriormente, o Tutor Presencial, por ser uma nova categoria profissional, encontra-se em uma situação de incerteza sobre seus direitos profissionais.

Dentre os respondentes, apenas um afirmou não ter utilizado os serviços de tutoria, enquanto que os demais, 22 respondentes, confirmaram sua utilização. Tonnetti (2012) faz um levantamento sobre as formas que esses profissionais são concebidos dentro das estruturas institucionais, a partir de análise bibliográfica. $\mathrm{O}$ autor destaca que:

Se não há relação professoral sem acompanhamento de alunos, devemos entender a tutoria como central no processo de ensino à distância, como condição sine qua non para que o ensino se efetive. Defendemos que, e apesar das dificuldades, os professores-tutores são os grandes responsáveis por conduzir os cursos na maioria dos modelos de ensino à distância estabelecidos $-[\ldots]$. Ainda que por vezes não considerados como verdadeiros mestres dentro dos sistemas em que atuam, os professores-tutores - muitas vezes acumulando tarefas de bedel virtual e docente - são os principais responsáveis e pontas de lança da educação a distância. (TONNETI, 2012, p.14)

Nesse sentido, retorna-se a uma incerteza sobre os fazeres docentes desse profissional, tendo em vista que há uma desvalorização sobre o tutor, mesmo que, para os alunos, ocorra uma valorização por ser o profissional que está lhes acompanhando durante o curso.

A respeito da perspectiva dos alunos sobre a atuação do Tutor Presencial, todos a avaliaram entre regular e ótima (Figura 4). De modo geral e levando em conta os resultados dos itens "Bom" e "Ótimo", pode-se perceber atuação dos tutores foi relevante na formação dos alunos respondentes. 


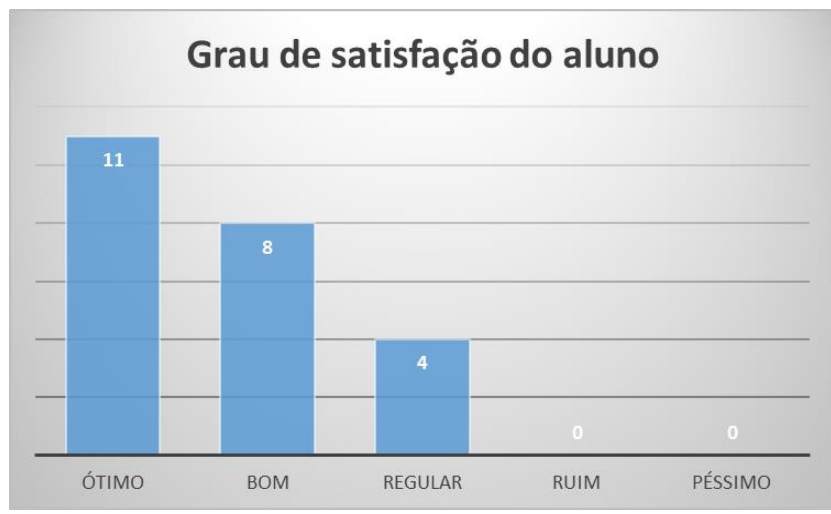

Figura 4 - Grau de satisfação do aluno

Fonte: o pesquisador

Quando questionados, especificamente, sobre a importância do Tutor Presencial para sua formação, os respondentes apresentaram diversas respostas que apresentamos abaixo (Tabela 1) as que consideramos relevantes, grifando trechos importantes para o desenvolvimento da pesquisa:

Tabela 1: Respostas sobre a importância da tutoria

\section{Qual a importância do TUTOR PRESENCIAL para sua formação no curso de} licenciatura?

Além de tirar as dúvidas sobre o conteúdo, a troca de experiências é muito importante.

Em minha jornada acadêmica foi composta até o momento por dois tutores, o primeiro trazia informações atualizadas sobre nossa área de formação, nos instigava a aprender cada vez mais, já o segundo tutor apenas faz a "tutoria", ou seja, revisa questões, aplica prova e explica trabalhos pertinente ao currículo, sem acrescentar algo a mais para nossa formação. Com tudo é importante um tutor que acrescente o "algo a mais" para a formação, que nos faça sair do currículo do curso, com fatos atualizados e que realmente venham a acrescentar para nossa formação.

Faz toda a diferença auxiliando nas dúvidas que surgirem

É importante para estabelecer relações com a matéria estudada, resoluções de dúvidas.

Acredito que seja o elo entre o polo presencial e a universidade. Ter a possibilidade de ter o contato físico e online com o tutor auxilia o alun@ nesse processo de aprendizagens.

De extrema importância, pois nos auxilia e incentiva. É uma peça fundamental em nosso polo no curso de Espanhol.

Um tutor deve orientar o grupo nas atividades e fazer a comunicação entre o prof. $\mathrm{E}$ o aluno. Daí sua importância durante um curso a distância. Ser um mediador.

A presença do Tutor Presencial é de extrema importância pois, conduz os primeiros contatos com os recursos específicos do curso em questão. Cabe destacar (na minha visão) como a mais importante das funções, o papel de orientar os acadêmicos no que se refere a organização do estudo: incentivo e estímulo durante o processo de aprendizagem, incluindo um feedback mais rápido das atividades. Ainda, lembro perfeitamente que além das atribuições em sala (nos dias de teleaulas), minhas tutoras eram encarregadas de disponibilizar informativos importantes, dentre outras atividades mais burocráticas.

Meu tutor foi de suma importância para sanar dúvidas no momento da aula e, para falar da profissão.

Fonte: o pesquisador 
As falas dos alunos demonstram a importância do Tutor no processo de ensino aprendizagem, mesmo que fossem encarregado de outras tarefas administrativas e/ou burocráticas no período em que estava sendo visto como "professor".

Diante da questão de que esse profissional é tutor, e ao mesmo tempo, docente, tem-se, segundo Pérez Gómez (2015), um novo paradigma a ser pensado no que se refere à função do novo docente:

\begin{abstract}
A função docente, obviamente, terá de experimentar uma transformação tão radical quanto o resto dos componentes do sistema educacional. A visão terá de mudar de uma concepção do docente como um profissional definido pela capacidade de transmitir conhecimentos e avaliar resultados para a de um profissional capaz de diagnosticar as situações e as pessoas; elaborar o currículo ad hoc e preparar materiais; desenvolver atividades, experiências e projetos de aprendizagem; configurar e criar os contextos de aprendizagem; avaliar processos e monitorar o desenvolvimento integral dos indivíduos e dos grupos. Evidentemente, este docente exige competências profissionais mais complexas e distintas das tradicionalmente exigidas, para poder enfrentar uma atividade tão rica quanto difícil: provocar, acompanhar, questionar, orientar e estimular a aprendizagem dos alunos (p.141).
\end{abstract}

Nesse novo contexto, em que mudam as formas como se dão as experiências docentes, o tutor deve estar apto a desenvolver essas novas competências para alcançar os objetivos pedagógicos necessários a uma era digital (PÉREZ GÓMEZ, 2015).

Como colocado por um dos participantes da pesquisa, "além das atribuições em sala (nos dias de teleaulas), minhas tutoras eram encarregadas de disponibilizar informativos importantes, dentre outras atividades mais burocráticas", salientam-se as contribuições de Pérez Gómez. Entende-se que há uma responsabilidade que abrange, em alguns casos, além daquelas restritivas a um modelo antigo de professor, pois o Tutor Presencial, também, necessita acompanhar as aprendizagens do aluno, tanto no espaço presencial quanto no espaço digital (ambiente virtual de aprendizagem).

Por se tratar da formação de professores, mesmo ocorrendo na modalidade de Educação a Distância, considera-se pertinente compreender que "a formação será legítima então quando contribuir para o desenvolvimento profissional do professor no âmbito de trabalho e de melhoria das aprendizagens profissionais" (IMBERNÓN, 2010, p. 47). Nesse sentido, as palavras de um dos respondentes, que expressam a expectativa de que o tutor o auxilie a ir além do currículo, demonstram a importância do tutor desenvolver determinadas competências para que possa auxiliar o estudante no processo de formação e constituição de uma identidade como docente.

Desse modo, além da formação realizada pelo aluno, deve-se levar em conta a formação do tutor, pois, de acordo com Imbernón:

Falar de desenvolvimento profissional, para além da formação, significa reconhecer o caráter profissional especifico do professor e a existência de um espaço onde este possa ser exercido. Também implica reconhecer que os professores podem ser verdadeiros agentes sociais, capazes de planejar e gerir o ensino-aprendizagem, além de intervir nos complexos sistemas que constituem a estrutura social e profissional. (IMBERNÓN, 2010, p. 48)

O profissional que atua na qualidade de Tutor Presencial, que não tem o título de docente dentro de seu retrato funcional, acaba por atuar em muitos casos como professor e não é raro o caso em que tem uma qualificação igual ou superior a exigida para atuar como professor. 
Assim, a profissão de Tutor retorna ao "limbo" no que se refere às suas atribuições, à realização de uma prática junto aos alunos, mesmo que isso não seja definido junto às instituições, pois existem questões trabalhistas que dão certos direitos ao profissional contratado como Professor.

Finalmente, quanto ao último item do questionário (Tabela 2), no qual foi aberto espaço para os respondentes realizarem manifestações que considerassem relevantes, as quais não foram possíveis de fazê-las durante o questionário.

Tabela 2 - Manifestações dos respondentes

Espaço para manifestação de algo que não pode ser contemplado dentro das questões anteriores.

A tutora foi a mesma do início ao fim, tinha a formação na área e atendia a todas as disciplinas. Senti falta de ter tutores presenciais especialistas em cada disciplina.

Meu tutor nem sempre entendia do assunto para nos auxiliar e a faculdade dizia que não era obrigação dele saber. Mas acredito que sim, teria que entender do assunto e ser o professor neste dia de encontro presencial

Durante a minha experiência com tutoras presenciais, senti falta de termos uma relação professor/aluno, no sentido de termos realmente aula e não um mero encontro para receber notícias e orientações da universidade.

Tem que ter Tutor Presencial para garantir um aprendizado de Excelência.

O Tutor Presencial é fundamental para integrar o grupo

Ainda que teu foco seja na licenciatura, atualmente curso uma [especialização] lato sensu totalmente a distância e percebo a necessidade de uma tutora presencial, justamente por esta falta de contato físico. Desta forma, exige uma maior disciplina para que a aprendizagem ocorra de maneira significativa.

Fonte: o pesquisador

No momento em que foi dada a oportunidade aos respondentes para expressar suas perspectivas acerca da atuação dos tutores, ocorreu uma queixa sobre a formação a distância que, nas palavras de alguns, faltava uma relação de professor-aluno. Além disso, outros abordaram a necessidade de o aluno se tornar mais disciplinado no acompanhamento das aulas para não deixar acumular tarefas e prejudicar a aprendizagem.

Entretanto, o que mais se ressaltam são palavras como: "Meu tutor nem sempre entendia do assunto para nos auxiliar e a faculdade dizia que não era obrigação dele saber" (Respondente 17, instituição pública). Esse relato evidencia o que já foi apontado sobre as regras próprias de cada instituição quanto à formação, seleção e atuação do Tutor Presencial no acompanhamento e orientação dos alunos em processo de formação inicial.

Já o respondente 19, de uma instituição pública, expressa que "[...] senti falta de termos uma relação professor/aluno, no sentido de termos realmente aula e não um mero encontro para receber notícias e orientações da universidade". De acordo com essas palavras, existia por parte do aluno a necessidade de um processo mais dialógico quanto à aula e não só a processos de divulgação de informações. Ressalta-se que ambos os alunos eram da mesma instituição. Nesse sentido, conforme Tardif (2012, p. 118), no que respeita à prática pedagógica,

[...] na nossa opinião, à dimensão instrumental do ensino: ela é essa prática concreta, essa prática que está sempre situada num ambiente de trabalho, que consiste em coordenar diferentes meios para produzir resultados educativos, 
isto é, socializar e instruir os alunos em interação com eles no interior de um determinado contexto, tendo em vista atingir determinados objetivos, finalidades, em suma, determinados resultados.

A prática professoral, então, deve estabelecer mais do que simplesmente dar os recados. Porém, dentro de uma estrutura deficitária em que não se contempla, ou bonifica esse procedimento, acaba-se por ter tutores que não estão capacitados para trabalhar com os alunos dentro dessas perspectivas.

\section{Considerações Finais}

A partir do estudo desenvolvido, considera-se relevante tecer algumas reflexões sobre o papel do Tutor Presencial e suas atribuições. É possível perceber que, no discurso dos alunos, há uma dicotomia entre ser professor e ser Tutor Presencial. Porém, dentro das atribuições que narram sobre o profissional, podem ser caracterizados como professores e, além disso, evidenciou-se o desejo de que o tutor realmente atue como professor.

Destaca-se, ainda, que, muito comumente, o Tutor Presencial não possui formação adequada, conforme constatado pelo relato dos participantes, para realizar as atividades propostas e/ou responder as dúvidas colocadas pelos alunos nos encontros presenciais.

A discussão sobre a atuação do Tutor Presencial, ainda, carece de um aprofundamento maior, envolvendo, principalmente, as atribuições legais do sujeito, tendo em vista as atividades singulares que este realiza junto dos estudantes, as quais podem caracterizar outras denominações profissionais. Nesse sentido, sugere-se uma análise dentro do campo das legislações trabalhistas para fins de que possam garantir ao profissional Tutor amparo legal referente as atividades que executa junto aos alunos.

\section{Referências}

ALMEIDA, Leonardo Rocha. A experiência da tutoria presencial em cursos de formação continuada docente oferecidos a distância. Redin - Revista Educacional Interdisciplinar. Taquara, v4, n1, p. 1-4, novembro 2015.

BRASIL. Lei 9.394, de 20 de dezembro de 1996. Estabelece as Diretrizes e Bases da Educação Nacional. Disponível em: http://portal.mec.gov.br/setec/arquivos/pdf1/proejalei9394.pdf Acesso em 15 set. 2016

BOGDAN, R; BIKLEN, S. Investigação qualitativa em educação: uma introdução à teoria e aos métodos. Porto: Porto Editora, 1994.

EMERENCIANO, Maria do Socorro. SOUSA, Carlos Alberto Lopes. FREITAS, Lêda Gonçalves. Ser Presença como Professor, Educador e Tutor. Colabor@ - Revista Digital da CVA-Ricesu, Brasilia, v.1, n.1, p. 4-11, ago. 2001.

IMBERNÓN, Francisco. Formação docente e profissional: formar-se para a mudança e a incerteza. Tradução Silvana Cobucci Leite. 8ed. São Paulo: Cortez, 2010

LÜDKE, Menga; ANDRÉ, Marli E.D.A. Pesquisa em Educação: abordagens qualitativas. 2ed. Rio de Janeiro: E.P.U., 2013. 
PÉREZ GÓMEZ, Ángel I. Educação na era digital: a escola educativa. Porto Alegre: Penso, 2015.

SILVA, Renata; URBANESKI, Vilmar. Metodologia do Trabalho Científico. Indaial: ASSELVI, 2009

TARDIF, Maurice. Saberes Docentes e Formação Profissional. 13ed. Petrópolis, RJ: Vozes, 2012.

TONNETTI, Flávio Américo. Tutor é Professor: Algumas Considerações Sobre O Trabalho Docente Na Educação A Distância. In: Anais do Simpósio Internacional de Educação a Distância. São Carlos. 2012. 